\title{
ANTIPLATELET THERAPY AND EXODONTIA: FAR AWAY FROM A DEFINITE CONCLUSION
}

\author{
HAMIDREZA KARIMI-SARI*, MOHAMMAD SAEID REZAEE-ZAVAREH
}

Students' Research Committee, Baqiyatallah University of Medical Sciences, Tehran, Iran. Email: dr.karimih@yahoo.com/hrkarimisari@bmsu.ac.ir

\section{Dear Editor,}

We read a review article about antiplatelet therapy and dental management in your journal [1]. Kumar concluded that patients taking dual antiplatelet therapy have an increased risk for post-operative bleeding complications.

The focus question of this article contains many other smeller questions. We recently answered one of these questions in our study; one tooth extraction is safe in patients taking aspirin and clopidogrel during 1 year after percutaneous coronary intervention with stenting [2]. However, many questions remained without answer. Is two teeth extraction safe in these patients? What about more than two teeth extraction or in patients taking other antiplatelet drugs for other indications? What about other dental interventions? For answering each of these specific questions, we need to design a prospective original study, with enough sample size, and comparing the results with a matched control group.

Furthermore, there are many confounders for bleeding after exodontia (e.g., dentist's skill, type of antiplatelet drug and its manufacturing company, indication and duration of taking antiplatelet therapy, number and kind of extracted teeth, and dentist's skill) $[2,3]$. Controlling these confounders needs prospective studies focusing on a specific group of patients. For example, patients taking unique dose and type of antiplatelet drug for a unique indication and duration, undergoing unique dental intervention by unique dentist. Then, this result could be compared with a group of healthy subjects undergoing same dental intervention by the same dentist. Hence, we do not have enough evidence to make a definite conclusion about what we should do in case of dental intervention for patients taking antiplatelet therapy.

\section{REFERENCES}

1. Kumar S. Dental management of patients on antiplatelet therapy: Literature update. Asian J Pharm Clin Res 2016;9(3):26-31.

2. Sadeghi-Ghahrody M, Yousefi-Malekshah $\mathrm{SH}$, Karimi-Sari $\mathrm{H}$, Yazdanpanah H, Rezaee-Zavareh MS, Yavarahmadi M. Bleeding after tooth extraction in patients taking aspirin and clopidogrel $\left(\right.$ Plavix $\left.^{\circledR}\right)$ compared with healthy controls. Br J Oral Maxillofac Surg 2016;54(5):568-72.

3. Karimi-Sari H, Rezaee-Zavareh MS. Pharmacology: Confounders for bleeding. Br Dent J 2016;220(12):611.

(C) 2016 The Authors. Published by Innovare Academic Sciences Pvt Ltd. This is an open access article under the CC BY license (http://creativecommons. org/licenses/by/4. 0/) DOI: http://dx.doi.org/10.22159/ajpcr.2016.v9i6.14065 